\title{
The optimal model and market mechanism design of wide area multiple energy allocation
}

\author{
Dunnan Liu, a , Hao Chen ${ }^{2, a}$, Rui Ge ${ }^{2, b}$, Siyuan Zhang ${ }^{2, c}$, Xinfan Jiang ${ }^{2, d}$, \\ Zhigang Liu $^{2, e}$ \\ ${ }^{1}$ North China Electric Power University, Beijing, China \\ ${ }^{2}$ State Grid Hunan Electric Power Company, Changsha, Hunan province, China \\ aliudunnan@163.com, ${ }^{\text {b}} 715437085 @ q q . c o m$
}

\begin{abstract}
Keywords: multiple energy, trans-regional and trans-provincial, electricity trade, market mechanism
\end{abstract}

Abstract. Energy resources optimal allocation of wide area market mechanism in our country is still not perfect at present, part of management policy restricts the marketization organizing and conducting about trans-regional and trans-provincial of electricity trade, which was unable to adapt to the wide area optimal allocation requirement of the resources. In this paper, a target function of the optimal social utility, the largest trading volume was constructed. Also, the power grid safety, continuous and reliable power supply and power supply quality were taken as the constraints of the optimal allocation model of wide area multiple energy. Moreover, the solution algorithm based on the relevant provisions of the trans-regional and trans-provincial concentration matchmaking transaction was established. Finally, according to typical problems existing in the optimal allocation of wide area multiple energy, constructed the market mechanism which can improved the wide area optimal allocation effectively. The model and the market mechanism laid a foundation for breaking the bound of the existing mechanism and the barriers that hindering the power transaction development. Also, it was the basis of promoting the optimization and adjustment of the management policy.

\section{Introduction}

Recently, the optimal allocation of wide area multiple energy implements the national energy strategy, it ensuring the supply of energy and the use of hydropower and other clean resources, promoting the wider area and more large-scale resource optimal allocation. It's also promoting the construction of the power market and enhancing the awareness of all parties concerned [1].

There are two forms in the optimal allocation of wide area multiple energy: one is the point-to-network transaction, which all have formulated the direction, proportion and electricity price of consumption by government for the large scales Hydropower Station, coal power and nuclear power station such as the three gorges, yangcheng and qinshan directional given consumption transaction spanned across the trans-regional and trans-provincial. The other is the network-to-network transaction, a part of the power delivery mode and price is determined by government, the other part of the power delivery mode is formed in market, and the transmission power plant price execute pool purchase price according government official reply [2].

There are some problems in the optimal allocation of wide area multiple energy at present: 1)The barrier of transaction between different provinces still exists. 2)The benefit is hardly fair coordinate between the area of power generation enterprises and local power generation enterprises, and between the purchase of electric power company and the sale of electric power company.3)Scientific and reasonable price mechanism has not yet been established. This paper will focus on the problem above, building the optimal model and market mechanism design of wide area multiple energy allocation.

\section{The basic connotation of the optimal allocation of wide area multiple energy}

The optimal allocation of wide area(the trans-regional and trans-provincial electricity trade) multiple energy(coal-fired thermal power, natural gas thermal power, hydropower, nuclear power, 
pumped storage, wind power, photovoltaic power, biomass energy, ocean energy, geothermal energy ) means :power enterprises(multiple energy generation enterprises, regional power grid companies, province power company) and power enterprises(or electric power big users ) outside the province(or regional) to carry out the trading of electric power and energy, which includes multiple energy generation enterprises commissioned by the province power grid enterprises with the provinces and regions outside of the power grid enterprise of electricity power trading.

The transaction type (trade variety) of the optimal allocation of wide area multiple energy include:

1) Power purchasing and selling trading by the trans-regional and trans-provincial between the power grid enterprises, generation enterprises and power enterprises.

2) Between the multiple energy generation enterprises of all kinds power generation right trading across the trans-regional and trans-provincial.

3) Transfer transaction and buying back deal of power purchasing and selling transaction contract by the trans-regional and trans-provincial.

4) The trans-regional and trans-provincial power users directly deal with multiple energy generation enterprises.

The optimal allocation of wide area multiple energy of market object is divided into the sale, transmission and purchase. Selling electricity subject is multiple energy enterprise which has the power generation business license, and entrusted by power grid enterprises of multiple energy power generation company. Transmission subject is multiple energy enterprise which has the power transmission business license, purchase subject is the provincial grid corporation and qualified independent placement of electric enterprises and power users.

\section{The model and brokerage algorithm of the wide area multiple energy optimal allocation model}

Assuming the concentration matchmaking transaction market has $\mathrm{n}$ electricity selling party (power enterprise or agency), and $\mathrm{m}$ purchaser (provincial power company or power users). The i sell electricity side to declare the sale of electricity (here in after referred to as the sale of electricity) and price respectively $Q_{S, i}$ and $P_{S, i}$, and the j purchaser to declare the purchase of electricity (here in after referred to as the purchase of electricity) and price respectively $Q_{B, j}$ and $P_{B, j}$. The constraint conditions of cross the trans-regional and trans-provincial power transaction model for:

$$
\begin{array}{ll}
\text { (a) } \sum_{i=1}^{n} Q_{i j} \leq Q_{B, j}, j=1,2, \mathrm{~L}, m & \text { (c) }\left|\mathrm{P}_{1}\right| \leq \mathrm{P}_{\mathrm{l}, \max }, 1=1,2, \mathrm{~L} \mathrm{~L} \\
\text { (b) } \sum_{j=1}^{m} Q_{i j} \leq Q_{S, i}, i=1,2, \mathrm{~L}, n & \text { (d) } \mathrm{V}_{\mathrm{k}, \min } \leq \mathrm{V}_{\mathrm{k}} \leq \mathrm{V}_{\mathrm{k}, \max }, \mathrm{k}=1,2, \mathrm{~L} \mathrm{~N}
\end{array}
$$

Constraints (1) in the first type (a) for the purchase of electricity in a power purchase $\mathrm{j}$ declaration constraints, The type second (b) for the i electricity sale to declare the sale of electricity constraints, The third fourth and fifth type(c), (d), (E) is power system security constraints, continuous reliable power supply and power quality constraintof grid.

The construction of objective functions as follows:

$$
\left\{\begin{array}{l}
\max \sum_{i=1}^{n} \sum_{j=1}^{m}\left(P_{B, j}-P_{S, i}-C_{i j}\right) \times Q_{i j} \\
\max \sum_{i=1}^{n} \sum_{j=1}^{m} Q_{i j}
\end{array}\right.
$$

$C_{i j}$ as the transaction cost between the sale and purchase side of electricity i and j.(1) and (2) is constituted by social utility optimization and the largest volume of across the trans-regional and trans-provincial electricity trade model.

The following algorithm model: 
1) If $C_{i j}=0$ or $C_{i j}=$ constant, namely: no transaction costs (not consider the transaction cost, or transaction costs are further considered) or between any two power purchase and sale of electricity side are same.

The first step: the purchase of electricity in accordance with the quotation from high to low order scheduled transaction priority, sell electricity side according to the quotation from low to high prioritization, "high-low matching" matchmaking, matchmaking process will meet one of the following three cases:(a)all the purchaser declared purchasing electricity quantity have all deal;(b)all the seller declared selling electricity quantity have all deal; (c)quotation difference is negative, not traded power purchase price is lower than no transaction of the sale of electricity price.

The second step: after the matchmaking process finished, checking whether meet the safety constraint condition, if it not satisfied, from the final transaction "the pair of trading" reverse starting, adjustment and congestion related "the pair of trading" transaction power, until the meet the constraint condition.

The third step: check whether the condition of matchmaking process end is satisfied, if it is, the result is meeting the matchmaking transaction security constraints; if not, then according to the no transaction power purchaser and seller data, into the first step.

2) If $C_{i j} \neq 0$, and $C_{i j} \neq$ constant

Prioritize according to the differences between quotation difference of purchaser and sellers trade costs $\circ$ There are $\mathrm{n}$ sellers and $\mathrm{m}$ buyers, and establish matching matrix $\mathrm{P}$, matrix element $\overline{P_{i, \mathrm{j}}}=P_{B, j}-P_{S, i}-C_{i j}$. Prioritize the $\mathrm{n} \times \mathrm{m}$ trades according to the differences between quotation difference and trade costs.

First step: search the maximum matrix elements $\overline{\mathrm{P}_{\mathrm{k}, \mathrm{v}}}=\max \left(\overline{P_{i, \mathrm{j}}}\right)$, if $\overline{\mathrm{P}_{\mathrm{k}, \mathrm{v}}} \geq 0$, then matchmaking the trade between $P_{B, \mathrm{v}}$ and $P_{S, \mathrm{k}}$. If the purchasers of buyer $P_{B, \mathrm{v}}$ have been all satisfied, then delete the v-th column of the matrix; if the sales of $P_{S, \mathrm{k}}$ have been all satisfied, then delete the k-th line of the matrix. After the completion of the transaction match, renew the data of both purchasers and sellers, and those who have finished their deal could be deleted in the matching matrix.

The second step: start from the step one according to the new data from both purchasing and selling, repeat the trade matching based on principles above, until there is no possibility to match up, namely: until the matrix is completely eliminated, or all of the matrix elements is less than zero, then the match making process ends. After the matching process, check whether the conditions satisfy the security constraints; otherwise, from the final transaction "trading pair" reverse starting, adjustment and congestion related "trading pair" transaction power, until the meet the constraint condition.

The third step: check weather all the differences which are more than zero conclude a transaction, if it is, the result is meeting the matchmaking transaction security constraints; if not, then according to the no transaction power purchaser and seller data into the first step.

\section{Market mechanism design of the wide area multiple energy optimal allocation}

\section{Forming mechanism of power price}

(1)Sending end price mechanism. Opening the pool purchase price in power plant of the trans-regional and trans-provincial trade, to establish sending and purchasing electricity price market negotiation formation mechanism in the trans-regional and trans-provincial trade

(2)Accepting end price mechanism. Establishing a price mechanism which fully reflects the power supply and demand and low carbon energy saving and emission reduction, prefect cross the trans-regional and trans-provincial power transaction price by linkage and transmission mechanism of the sending end and the accepting end.

(3)Peak-valley TOU power price mechanism. To establish peak and valley electricity price mechanism price of pool purchase price and terminal sales price, through price signals to guide the 
power enterprises to reasonable selection of operation mode, reasonable compensation for the cost of power generation enterprises peaking regulation.

\section{The main transaction benefits coordination mechanism}

(1)The purchase of electricity power company profit sharing mechanism

In order to maintain the power purchasing power company interests and balance between the purchases of electricity power company interests, respectively set up distribution of interests in each purchase of electricity province account. As purchase province thermal power desulfurization stake electrovalence for reference, purchase price is lower than the thermal power desulfurization stake electrovalence price part out of $50 \%$ funds into the interests allocation account to purchase electricity provinces.

(2)Sending electricity province power generation business interests sharing mechanism

For maintain the interests of sending electricity province power generation business, in each transmission province established interests allocation account. The stake electrovalence price to send electricity outside the province as a reference, to send electricity price than the stake electrovalence price part out of 50\% high interest allocation of funds into the account to send electricity outside the province, when sending power plant electricity price is lower than the stake electrovalence price, to compensate the delivery power plant, and thus adjust the risk of cross the trans-regional and trans-provincial trading price fluctuation for delivery power plants. If the delivery generating power plant generate have influence on the external power supply, power plant can also consider compensation.

\section{Ancillary service compensation mechanism}

In the allocation optimal of wide area multiple energy trade cross the trans-regional and trans-provincial, electricity purchasing area thermal power of peak load regulation performance better provide ancillary services for sending electricity generation enterprises province, reasonable economic compensation for ancillary services is an important mechanism guarantee to ensure the sending end energy smooth consumption and safe operation of the system. Through the interests allocation account funds of transmission and purchasing province give compensation to generation enterprises which provide peak regulation ancillary service.

\section{Summary}

After the analysis of the basic connotation of the wide area multiple energy optimal allocation, constructing the trans-regional and trans-provincial electricity trade model basic on the social utility optimization and the large of trading volume, then and aiming at the problems in wide area multiple energy configuration, constructing the corresponding market mechanism, to play the basic role of market allocation of multiple energy resources, then promoting the optimal allocation of multiple energy in the larger area.

\section{Acknowledgement}

This work was financially supported by the National Natural Science Foundation of China (71401055).

\section{References}

[1] SHANG Jin-cheng, ZHANG Li-qing. Research and Application of Technologies in Energy-Saving, Emission-Reducing and Optimal Resource Allocation of Electric Power System. Power system technology[J], 2007, 31(22), 58-63.

[2] XIE Qingyang, YING Liming, ZHU Yonggang. Competitive Power Market Mechanism Design Based on the Designing Economic Mechanisms Theory. Proceedings of the CSEE[J], 2014, 10, 1709-1716. 